\title{
Combined effect of silver nanoparticles and honey in experimental wound healing process in rats.
}

\author{
Guruvu Neeraja Rani ${ }^{1 *}$, Bandaru Narasinga Rao $^{2}$, Shamili $\mathbf{M}^{3}$, Jyothi Padmaja ${ }^{4}$ \\ ${ }^{1}$ Department of Research, Saveetha University, Thandalam, Chennai, Tamil Nadu, India \\ ${ }^{2}$ Department of Microbiology, Gayatri Vidya Parishad Institute of Health Care and Medical Technology, Marikavalasa, \\ Madhurawada, Visakhapatnam, Andhra Pradesh, India \\ ${ }^{3}$ Department of Pathology, Great Eastern Medical School and Hospital, Ragolu, Srikakulam, Andhra Pradesh, India \\ ${ }^{4}$ Department of Microbiology, Great Eastern Medical School and Hospital, Ragolu, Srikakulam, Andhra Pradesh, India
}

\begin{abstract}
Background: Wounds are still major problem in developing countries, and may impose severe complications and high cost for therapy. Hence, wound management still remains an important focus of researches. Plastic catheters coated with SNPs prevent biofilm formation. Papaya possesses antibacterial activity which might prevent the multiplication of wound infection causing bacteria. The objective of this study was to combined effect of honey and silver nanoparticles increases the rate of healing in wounds infected by Pseudomonas aeruginosa.

Material and methods: Eighteen healthy adult male Wistar albino rats weighing 250-300 g were used in this study. Excision wound model was used for this study. A wound of $500 \mathbf{~ m m}^{2}$ was created using a sterile scalpel by removing the skin on the dorsum of the abdomen of the all group. Clinical assessments included observations concerning the appearance, and the wound size was measured.

Results: The wound in all the three groups were almost same in the beginning. The percentage of wound closure on the fifth day was $0.86 \pm 0.11,0.91 \pm 0.18$ and $0.95 \pm 0.07$, On $\mathrm{d} 10$ still better wound closure was observed with a percentage there was a significant increase in healing and the percentage closure was $0.76 \pm 0.20,70.2 \pm 0.19$ and $71.15 \pm 0.18(P<0.001)$, on $\mathrm{d} 15$ the wound closure percentage was 20.18 $\pm 0.18,89.21 \pm 0.18$ and $94.31 \pm 0.20(P<0.001)$, for control, honey treated and honey $\pm \mathrm{Ag}$ Nps groups respectively with a high significance from control.

Conclusion: This study demonstrated the efficacy of multifloral honey mixed with silver nanoparticles in wound healing. Topical application of multifloral honey with silver nanoparticles accelerated the rate of wound healing by increasing the wound contraction compared with honey. The acceleration of wound healing rate and wound contraction through macroscopic and histological evolution on d 1, 5, 10 and 15. Hence, honey mixed with silver nanoparticles is potentially useful in dressing wounds.
\end{abstract}

Keywords: Honey, Silver nanoparticles, Antimicrobial property, Albino adult male Wistar rats, Pathogenic microbes, Wound healing.

\section{Introduction}

Till date, wound healing is an existing problem and research is going on in this area. Hence, wound management still remains an important focus of researches [1,2]. Wound healing is a set of coordinated response to tissue injury. It represents a dynamic physiological process initiated and influenced by many factors like homeostasis, inflammation, proliferation and remodeling phases [3].

At the site of wound, macrophages get activated and release growth factors, such as Platelet Derived Growth Factors (PDGF) and Vascular Endothelial Growth Factors (VEGF), which initiate the formation of granulation tissue. Macrophages have a key role in inflammation and repair of wounds. Platelets facilitate the formation of a homeostasis plug and activate fibroblasts for re-epithelisation of wounds. Within $1^{\text {st }}$ to $2^{\text {nd }}$ day of injury, epidermal cells initiate margination of wound. New granulation tissue begins to invade the wound gap after $4^{\text {th }}$ day and numerous new capillaries grow through the new stroma with its granular appearance $[4,5]$. The most common infections in the wounds are caused by Staphylococcus aureus, Pseudomonas aeruginosa, Enterococcus species and Escherichia coli [6]. 
Honey is a natural and freely available viscous food substance in nature. A vast amount of scientific evidence supports its nutritional, medicinal and antimicrobial properties [7]. Honey has antioxidants, anti-inflammatory, anti-allergic, antithrombotic, vasodilator activity and wound healing properties without harmful effects to host tissues [8]. It has bacteriostatic and bactericidal property because of its high osmolarity [9]. Previous studies revealed that honey is effective against antimicrobial resistant bacteria such as Staphylococcus aureus and Pseudomonas aeruginosa on wounds [10,11].

The silver nanoparticles have various and important applications. It has been reported that silver nanoparticles (SNPs) are non-toxic to humans and most effective against bacteria, virus and other eukaryotic micro-organism at low concentrations without any side effects [12]. Moreover, several salts of silver and their derivatives are commercially manufactured as antimicrobial agents [13]. In hospitals, infection is the most common complication and cause of death in patients. Therefore, antibacterial effects of silver have been incorporated into various medical applications. Plastic catheters coated with SNPs prevent biofilm formation. Papaya possesses antibacterial activity which might prevent the multiplication of wound infection causing bacteria [14]. Hence, an attempt was made in this present study to determine whether honey with silver nanoparticles can increase the rate of healing in wound pathogens in an experimental animal.

\section{Material and Methods}

\section{Study setting}

The study was conducted in the Department of Research and Development, Saveetha Institute of Medical and Technical Sciences (SIMATS), Chennai, India. After obtaining necessary approval from Institutional Animal Ethics Committee (Vide Ref. no SU/CLAR/RD/008/2016).

\section{Animals}

The animals were housed in individual metabolic cages and maintained in the temperature range of $24^{\circ} \mathrm{C}-27^{\circ} \mathrm{C}$ and humidity $40 \%-50 \%$ with natural light/dark cycle as per Committee for the Purpose of Control and Supervision of Experiments on Animals (CPCSEA) guidelines for laboratory animal research. They were provided with pellet food and water ad libitum.

\section{Experimental animals and study design}

Eighteen healthy adult male Wistar albino rats weighing 250-300 g were used in this study. Randomly selected rats were assigned to 3 (1-3) groups of 6 rats each. Rats in group 1 consider as control, group 2 consider as positive control and group 3 considered as experimental group. Sterile pasteurized multifloral honey for testing antibacterial activity was obtained from Bharat Unani Pharmacy, Hyderabad, India. Silver nanoparticles purchased from Hi-Q nanotechnology, Banglore, Karnataka. Bacterial strains to inoculate the wound were collected from Post Graduate Institute of Medical Education and Research, Chandigarh (India). Pseudomonas aeruginosa ATCC-27853, the common cause of wound infections. A six hour incubated bacterial culture suspension matching with 0.5 Mc-Farland scale standards were prepared (i.e. $10^{3} \mathrm{CFU}$ for $P$. aureginosa).

\section{Experimental wound preparation}

Excision wound model was used for this study. A wound of $500 \mathrm{~mm}^{2}$ was created using a sterile scalpel by removing the skin on the dorsum of the abdomen of the all groups [15] under isofluorane anaesthesia. The wounds were infected by instilling $100 \mu \mathrm{l}$ strains of $P$. aeruginosa. Evaluation every five days, i.e. on $\mathrm{d} 1,5,10$ and 15. Each wound was examined and photographs were taken after wound creation until healing was complete. Clinical assessments included observations concerning the appearance, and the wound size was measured.

\section{Procedure}

Untreated group was left without any treatment to serve as the untreated group 1 (control group), group 2 was treated topically $0.5 \mathrm{ml} / \mathrm{cm}^{2}$, while group 3 was treated with honey combine with silver nanoparticles (experimental group). On $\mathrm{d}$ $1,5,10$ and 15 of treatments, relevant groups had their wounds measured before tissues were excised.

\section{PERCENTAGE OF WOUND CONTRATION}

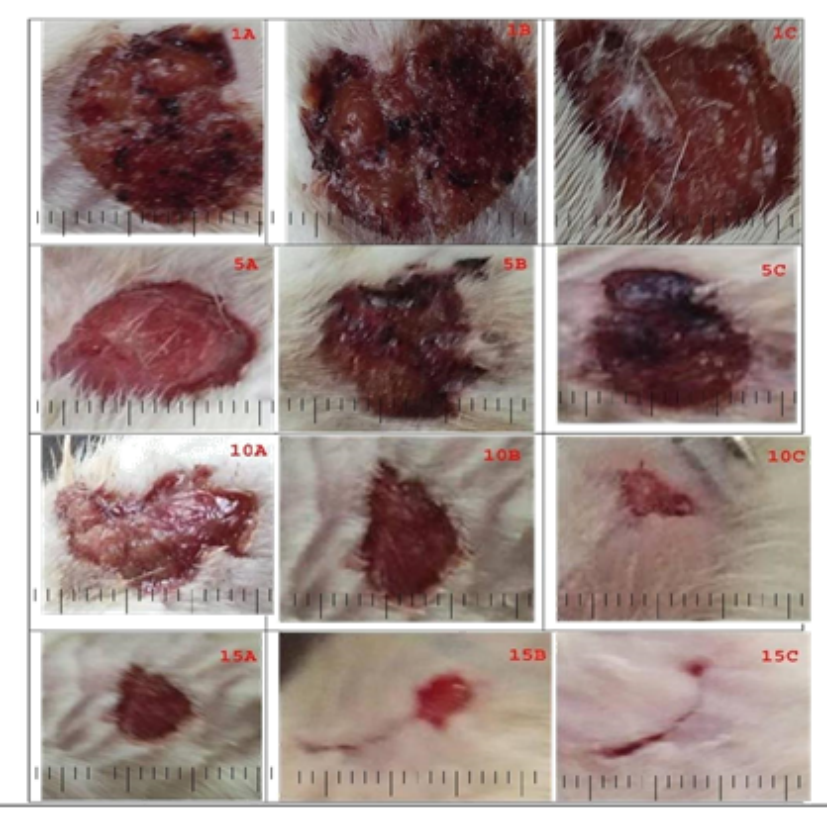

Figure 1. Size of excision wound appearance after treatments: Results from (1A), (5A), (10A) and (15A) of untreated group, (1B), (5B), $(10 B)$ and (15B) of treated honey, (1C), (5C), (10C) and (15C) of treated with honey+ $\mathrm{Ag} N \mathrm{NS}$.

\section{Rate of wound contraction}

Wound size was measured on every $5 \mathrm{~d}$ interval $\left(1^{\mathrm{st}}, 5^{\text {th }}, 10^{\text {th }}\right.$, and $15^{\text {th }} \mathrm{d}$ ) with the help of butter paper and graph paper and the percentage of wound contraction was calculated using the 
following formula (Figure 1). The percentage wound contraction was calculated by dividing the difference in wound area of a particular day from the first day by first day area and then multiplying it with hundred [16].

\section{Histological evaluation of healed wounds}

Excised tissue was fixed in 10\% formalin before histologically processed. Sections were made with Haematoxylin and Eosin ( $\mathrm{H}$ and $\mathrm{E}$ ) staining, assessment for histological features was observed under light microscope (40X) on $\mathrm{d} 1,5,10$ and 15 respectively.

\section{Ethical consideration}

The study protocol was approved by institutional animal ethical committee of Saveetha Institute of Medical and technical sciences SU/CLAR/RD/008/2016.

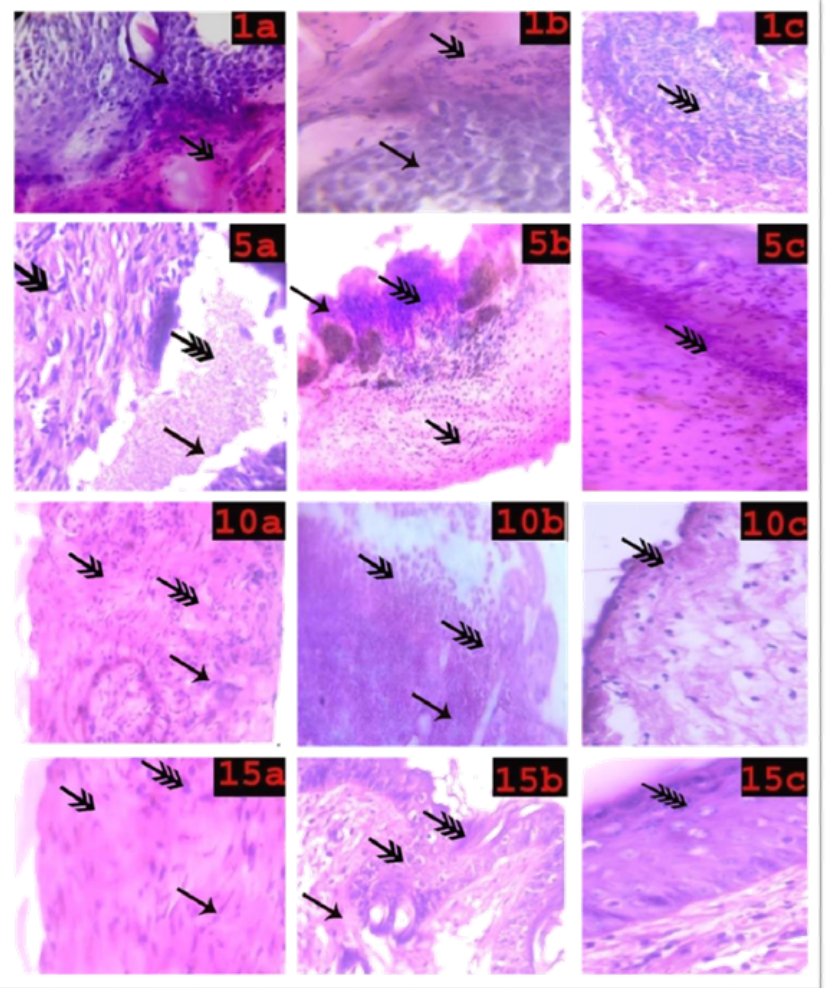

Figure 2. Histopathology of excision wound appearance after treatments: Results from (1a), (5a), (10a) and (15a) day of untreated group, (1b), (5b), (10b) and (15b) day of treated honey, (1c), (5c), (10c) and (15c) day of treated with honey + Ag NPS. $\rightarrow$ : Ulceration; $\rightarrow$ : Inflammation and edema lag in granulation tissue formation; $\leadsto$ : Reepithelialisation and collagenous matrix formation.

\section{Results}

The wound in all the three groups were almost same in the beginning. The percentage of wound closure on the fifth day was $0.86 \pm 0.11,0.91 \pm 0.18$ and $0.95 \pm 0.07$, on $\mathrm{d} 10$ still better wound closure was observed with a percentage there was a significant increase in healing and the percentage closure was $0.76 \pm 0.20,70.2 \pm 0.19$ and $71.15 \pm 0.18(\mathrm{P}<0.001)$, on $\mathrm{d} 15$ the wound closure percentage was $20.18 \pm 0.18,89.21 \pm 0.18$ and 94. $31 \pm 0.20(\mathrm{P}<0.001)$, for control, honey treated and honey $\pm \mathrm{Ag}$ Nps groups respectively with a high significance from control (Table 1).

\section{Histopathology evolution}

(1a-1c) sections showing ulceration and intense inflammation, treatment not yet started, (5a) sections show inflammation, edema and initial stage of angiogenesis (5b) sections showing sub epithelial hemorrhage, and (5c) decrease in inflammation edema and initial stage of angiogenesis, (10a) sections show lag in granulation tissue formation, (10b) and (10c) sections show thin layer of reepithelisation and granulation tissue formation, (15a) sections showing lag in reepithelisation, (15b) and (15c) Sections showing continuing reepithelisation and collagenous matrix formation (Figure 2).

Table 1. Percentage wound contraction of control, honey treated and honey+silver nanoparticles on infected wound model. Statistical analysis is done with one way ANOVA with Dunnett's test $P<0.05$ was considered statistically significant where $n 6$ in control honey treated and honey+silver nanoparticles.

\begin{tabular}{llllll}
\hline S. no & Parameter & Control & $\begin{array}{l}\text { Honey } \\
\text { treated }\end{array}$ & $\begin{array}{l}\text { Honey+AgNps } \\
\text { treated }\end{array}$ & $\begin{array}{l}\text { Statistical } \\
\text { analysis }\end{array}$ \\
\hline 1 & $5^{\text {th }} \mathrm{d}$ & $0.86 \pm 0.11$ & $0.91 \pm 0.18$ & $0.95 \pm 0.07$ & $\mathrm{P}=0.493$ \\
\hline 2 & $10^{\text {th }} \mathrm{d}$ & $9.76 \pm 0.20$ & $70.2 \pm 0.19$ & $71.15 \pm 0.18$ & $\mathrm{P}<0.001$ \\
\hline 3 & $15^{\text {th }} \mathrm{d}$ & $\begin{array}{l}20.18 \\
0.18\end{array}$ & $\pm 89.21 \pm 0.18$ & $94.23 \pm 0.20$ & $\mathrm{P}<0.001$ \\
\hline
\end{tabular}

\section{Discussion}

Wound healing is a dynamic physiological process occur after skin injury and requires interactions of different cell types, growth factors and structural proteins, macrophages, neutrophils, and fibroblast cells have important role in wound healing, It consists of four systematic steps of hemostasis, inflammation, proliferation, and maturation in experimental animals. Healing process was confirmed by microscopic and macroscopic studies. After skin ulcer cell reaction occurs, initially blood clotting, and degranulation of mast cells, release chemical mediators and inflammation phase occurs $[17,18]$. During any injury, the body responds by restoring tissue injury by the synthesis of connective tissue matrix at the site of wound. The wound is strengthened by the fibrous protein, collagen, which is the major component of extracellular matrix. The increase in hydroxyl proline content support the increased migration of fibroblast cells, epithelial cells and collagen for the synthesis of extracellular matrix. A decrease in hydroxyl proline can prolong the inflammatory phase of wound healing and then inhibits both epithelial regeneration and proliferation of fibroblast. Wound contraction is a necessary feature for the healing process [19].

Honey has been used since ancient times in wound healing [20]. Previous studies reported on honey treatment of wounds, ulcers and skin graft preservation, the importance of sterile, residue-free honey for medical use [21]. Clinical observations on the wound healing properties of honey [22]. Effect of honey 
on healing of Pseudomonas aeruginosa infected burn wounds in rats [23]. Effects of Acacia honey on wound healing in various rat models [24]. The effect of Teucrium polium honey on the wound healing and tensile strength in rats [25]. Evaluation of the effects of local application of thyme honey in open cutaneous wound healing [26]. The evidence supporting the use of honey as a wound dressing [27]. Antibacterial activity of honey on bacteria isolated from wounds [28]. My previous in vitro study is a prospective study of honey with reference to its anti-bacterial activity [29].

An effective and complete process of wound healing is critical for the general well-being of any patients. In recent times, tremendous progress has been made in discovering the cellular and molecular mechanisms underlying the wound healing process. In current clinical treatments of wounds and ulcers, medications such as topical antimicrobial agents are still relevant. Moreover, applying nanotechnology and incorporating knowledge of cellular, sub cellular events occurring during the typical healing process, could obviously get better future therapeutic interventions. Nanotechnology offers great opportunities for improving wound treatments. Antimicrobial activity of the silver nanoparticles has been reported, and it has been shown that their size and concentration define their effectiveness. Nanoparticles with sizes from 5 to $100 \mathrm{~nm}$ at a concentration of $40 \mu \mathrm{g} \mathrm{ml}^{-1}$ have been reported to have bactericidal effects on most tested strains [30]. Kim et al. studied the antimicrobial mechanism of silver nanoparticles for certain microbial species; the peptidoglycan layer is a specific membrane feature of bacterial species and not mammalian cells. Therefore, if the antibacterial effect of silver nanoparticles is associated with the peptidoglycan layer, it will be easier and more specific to use silver nanoparticles as an antibacterial agent, and suggested that the antimicrobial mechanism of silver nanoparticles is related to the formation of free radicals and subsequent free radical-induced membrane damage. The free radicals may be derived from the surface of silver nanoparticles and be responsible for the antimicrobial activity [31]. Silver nanoparticles (AgNPs) are the most widely studied among metal NPs. These NPs have been shown to enhance healing in a full-thickness excisional wound model in mice [32]. Wounds treated with silver nanoparticles completely healed in $25.2 \pm 0.72 \mathrm{~d}$ after injury, whereas those treated with antibiotics required $28.6 \pm 1.02 \mathrm{~d}(\mathrm{P}<0.001)$. This finding suggests that other factors are also involved in the mechanism of action of silver nanoparticles [33]. The wound in all the three groups were almost same in the beginning. The percentage of wound closure on the fifth day was $0.86 \pm 0.11$, $0.91 \pm 0.18$ and $0.95 \pm 0.07$, on $\mathrm{d} 10$ still better wound closure was observed with a percentage there was a significant increase in healing and the percentage closure was $0.76 \pm 0.20$, $70.2 \pm 0.19$ and $71.15 \pm 0.18(\mathrm{P}<0.001)$, on $\mathrm{d} 15$ the wound closure percentage was $20.18 \pm 0.18,89.21 \pm 0.18$ and $94.31 \pm$ $0.20(\mathrm{P}<0.001)$, for control, honey treated and honey $\pm \mathrm{Ag} \mathrm{Nps}$ groups respectively with a high significance from control. Histopathology evolution: (1a-1c) sections showing ulceration and intense inflammation, treatment not yet started, (5a) sections showing decrease inflammation, edema and initial stage of angiogenisis, (5b) and (5c) sections showing sub epithelial hemorrhage, decrease in inflammation edema and initial stage of angiogenesis, (10a) sections show lag in granulation tissue formation, (10b) and (10c) sections showing thin layer of reepithelisation and granulation tissue formation, (15a) sections showing lag in reepithelisation, (15b) and (15c) sections showing continuing reepithelisation and collagenous matrix formation.

\section{Conclusion}

This study demonstrated the efficacy of multifloral honey mixed with silver nanoparticles in wound healing. Topical application of multifloral honey with silver nanoparticles accelerated the rate of wound healing by increasing the wound contraction compared with honey. The acceleration of wound healing rate and wound contraction through macroscopic and histological evolution on d 1, 5, 10 and 15. Hence, honey mixed with Silver nanoparticles is potentially useful in dressing wounds.

\section{References}

1. Vidinsky B, Gal P, Toporcer T. Histological study of the first seven days of skin wound healing in rats. Acta Veterinaria BRNO 2006; 75: 197-202.

2. Aljady AM, Kamaruddin MY, Jamal AM, Mohd Yassim MY. Biochemical study on the efficacy of Malaysian honey on inflicted wounds: an animal model. Med J Islam Acad Sci 2000; 13: 125-132.

3. Strecker-McGraw MK, Jones TR, Baer DG. Soft tissue wounds and principles of healing. Emerg Med Clin North Am 2007; 25: 1-22.

4. Heldin C, Westermark B. Role of platelet-derived growth factor in vivo. Molecular and Cellular Biology of Wound Repair (2nd Edn.). Clark, RAF, Plenum Press New York. 1996; 249-273.

5. Clark R, Nielsen L, Welch M, McPherson J. Collagen matrices attenuate the collagen-synthetic response of cultured fibroblasts to TGF- $\beta$. J Cell Sci 1995; 108: 1251-1261.

6. Rajan S. Skin and soft-tissue infections: classifying and treating a spectrum. Cleve Clin J Med 2012; 79: 57-66.

7. Molan PC. The potential of honey to promote oral wellness. Gen Dent 2001; 49: 584-589.

8. Lusby PE, Coombes A, Wilkinson JM. Honey: a potent agent for wound healing? J Wound Ostomy Continence Nurs 2002; 29: 295-300.

9. Subrahmanyam M. Honey dressing accelerates splitthickness skin graft donor site healing. Indian J Surg 2015; 77: 261-263.

10. Ewnetu Y, Lemma W, Birhane N. Antibacterial effects of Apismellifera and stingless bees honeys on susceptible and resistant strains of Escherichia coli, Staphylococcus aureus and Klebsiella pneumoniae in Gondar, Northwest Ethiopia. BMC Complement Altern Med 2013; 13: 269. 
11. Cooper RA, Molan PC, Harding KG. The sensitivity to honey of Gram-positive cocci of clinical significance isolated from wounds. J Appl Microbiol 2002; 93: 857-863.

12. Jeong SH, Yeo SY, Yi SC. The effect of filler particle size on the antibacterial properties of compounded polymer/ silver fibers. J Mater Sci 2005; 40: 5407-5411.

13. Krutyakov YA, Kudrynskiy A, Olenin AY, Lisichkin GV. Extracellur biosynthesis andantimicrobial activity of silver nanoparticles. Russ Chem Rev 2008; 77: 233.

14. Shivananda NB, Pinto PL, Maharaj D. Wound healing activity of Carica papaya L. in experimentally induced diabetic rats. Indian J Exp Biol 2007; 45: 739-743.

15. Murthy S, Gautam MK, Shalini G, Purohit V, Sharma H, Goel RK. Evaluation of in vivo wound healing activity of bacopa monniera on different wound model in rats. Biomed Res Int 2013.

16. Sadaf F, Saleem R, Ahmed M, Ahmad SI, Navaidul Z. Healing potential of cream containing extract of Sphaeranthus indicus on dermal wounds in Guinea pigs. J Ethanopharmacol 2006; 107: 161-163.

17. Brölmann FE, Ubbink DT, Nelson EA, Munte K, van der Horst CM, Vermeulen H. Evidence-based decisions for local and systemic wound care. Br J Surg 2012; 99: 1172-1183.

18. Bowler PG. Wound pathophysiology, infection and therapeutic options. Ann Med 2002; 34: 419-427.

19. Arul VA, Kartha RB, Jayakumar R. A therapeutic approach for Diabetic wound healing using biotinylated GHK incorporated collagen matrices. Life Sci 2007; 80: 275-284.

20. Noori SA, Khelod SS, Thia NA, Ali NA. The safety and efficacy of a mixture of honey, olive oil, and beeswax for the management of hemorrhoids and anal fissure: a pilot study. Sci World J 2006; 6: 1998-2005.

21. Postmes T, van den Bogaard AE, Hazen M. Honey for wounds, ulcers, and skin graft preservation. Lancet 1993; 341: 756-757.

22. Seeefem B. Clinical observations on the wound healing properties of honey. J Surg 1988; 75: 679-681.

23. Hazrati M, Mehrabani D, Japoni A, Montasery H, Azarpira N, Hamidian-shirazi AR, Tanideh N. Effect of honey on healing of Pseudomonas aeruginosa infected burn wounds in rat. J Appl Anim Res 2010; 37: 161-165.

24. Iftikhar F, Arshad M, Rasheed F, Amraiz D, Anwar P, Gulfraz M. Effects of acacia honey on wound healing in various rat models. Phytother Res 2010; 24: 583-586.
25. Alizadeh AM, Sohanaki H, Khaniki M, Mohaghgheghi MA, Ghmami G, Mosavi M. The effect of teucrium polium honey on the wound healing and tensile strength in rat. Iran J Basic Med Sci 2011; 14: 499-505.

26. Nasrin T, Gholamereza H. Evaluation of the effects of local application of thyme honey in open cutaneous wound healing. Iran J Public Health 2017; 46: 545-551.

27. Molan PC. The evidence supporting the use of honey as a wound dressing. Int J Low Extrem Wounds 2006; 5: 40-54.

28. Subrahmanyam MAH, Pawar SG. Antibacterial activity of honey on bacteria isolated from wounds. Ann Burns Fire Disast 2001.

29. Neerajarani G, Rao BN, Sukumar E, Padmaja J, Misra AK. A prospective study of honey with special reference to its antibacterial activity. Int J Gene Med Pharm 2016; 5: 60-73.

30. Agnihotri SM, Mukherji SS. Size-controlled silver nanoparticles synthesized over the range 5-100 nm using the same protocol and their antibacterial efficacy. RSC Adv 2014; 4: 3974-3983.

31. Kim JS, Kuk E, Yu KN, Kim JH, Park SJ, Lee HJ, Kim SH, Park YK, Park YH, Hwang CY, Kim YK, Lee YS, Jeong DH, Cho MH. Antimicrobial effects of silver nanoparticles. Nanomedicine 2007; 3: 95-101.

32. Liu XL, Ho PY, Lui CM, Chen VC, Che YCM. Silver nanoparticles mediate differential responses in keratinocytes and fibroblasts during skin wound healing. Chem Med Chem 2010; 5: 468-475.

33. Ansari MA, Khan HM, Khan AA. Evaluation of antibacterial activity of silver nanoparticles against MSSA and MRSA on isolates from skin infections. Biol Med 2011; 3: 141-146.

\section{*Correspondence to}

Guruvu Neeraja Rani

Department of Research

Saveetha University

Tamil Nadu

India 